\title{
WEBER, MAX \\ El poder del Estado y \\ la dignidad de \\ la vocación académica
}

En: Revista

Colombiana de

Educación. (21) 90, págs. 5 a 99 .

Traducción: Yolanda

Ramírez-Prado y

Gonzalo Cataño.

Nota introductora:

Gonzalo Cataño.

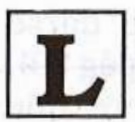

a compilación contiene 14 escritos del Maestro de la sociologia Max Weber, todos ellos relativos al fenómeno universitario; contempla planteamientos que propone el autor de 1908 a 1919. Como tal, representa una serie de reflexiones de un veteranu que puede presentar -en su momento- una postura crítica sobre la vidia de este ámbito académico, con el propósito de propugnar para éste acciones radicales tendientes al desarrollo de la ciencia y la cultura.

Me permito, una vez hecha esa mirada somera, detenerme en algunos aspectos que se pueden resaltar.

\section{La traduccion:}

Proviene, como se aclara en la Introducción, de la versión

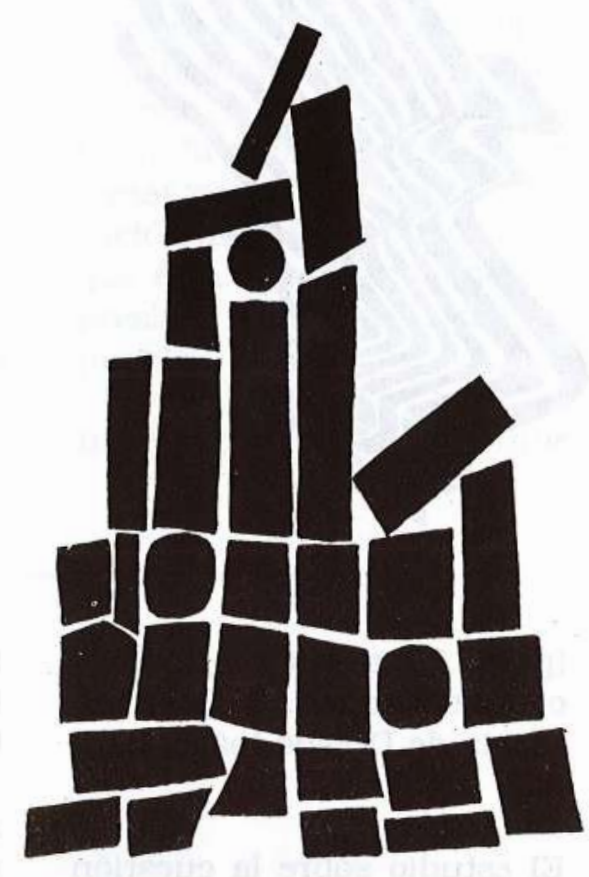

inglesa de Edwarda Shils, abundante en notas explicat1vas -en extremo pertinentesconfrontada con la versión francesa de L. Martín.

El profesor Cataño anota que la versión castellana -primera hasta donde se tiene noticiase debe entender como un proceso preparatorio "de apropiación de un pensamiento" como el de M. Weber (p.8).

Los traductores agregan en la versión castellana un Indice de nombres (págs. 93 a 99) que permite contextualizar los debates sostenidos por el autor en sus páginas.

En esta verslón se acogen dos textos previamente traducidos.

Este comienzo de "apropiación" del pensamiento de Weber tendrá que ser complementado, en algún momento, con la aparición de una traducción directa del alemán.

\section{Los temas estudiados:}

a. Weber se expresa con relación a "El caso Benhard". En estos análisis pone de presente las situaciones a que se vé precipitada la vida universitaria cuando p.e., en la selección de nuevos profesores se opera con base en criterios extraacadémicos. En la Alemania de la época las relaciones entre Ministerio de Enseñanza y Universidad pasó por un periodo crítico. En unos casos, como en el relativo a $\mathrm{L}$. Benhard, el Ministerio imponía profesores; en otros casos, los proponía ${ }^{1}$ en otros, aceptaba propuestas del

1 Ilustra, en este respecto la experiencia de E. Husserl. Por esta época a éste propuso el Ministerio de Enseñanza para 'profesor ordinario de filosofía" en la 
cuerpo docente universitario. Detalles de la complejidad de estas relaciones son materia de la polémica propuesta por Weber (págs. 11 a 25).

Las nefastas consecuencias, de lo que ocurre con la imposición de profesores a la universidad desde instancias extra-académicas, Weber las lleva a máxima caracterización en: A proposito del 'sistema Althoff' ${ }^{2}$ (págs. 49 a 52), el 'sistema Althoff' (págs. 53/4) y una vez más sobre el 'sistema Althoff' (págs. 67 a 70).

b. Esta polémica, en buena medida, la extiende y la profundiza el autor al analizar La pretendida 'libertad académica' de las universidades alemanas (págs. 27 a 30) y al caracterizar la libertad académica de las universidades (págs. 31 a 37). Una cuestión central a estos análisis podria formularse en los siguientes términos: ¿debe el profesor universitario defender una ideología (de Estado y, aún, de funcionarios del mismo) o radicalizar una actitud critica frente al presente viviente?

c. ¿Quéconsecuencia puede tener sobre el mundo de la vida universitaria la introducción de la "competencia" (...) libre el implacables? (vid. pág. 42). Es tema que se somete a estudio en Universidades americanas y alemanas: conferencia de Dresde

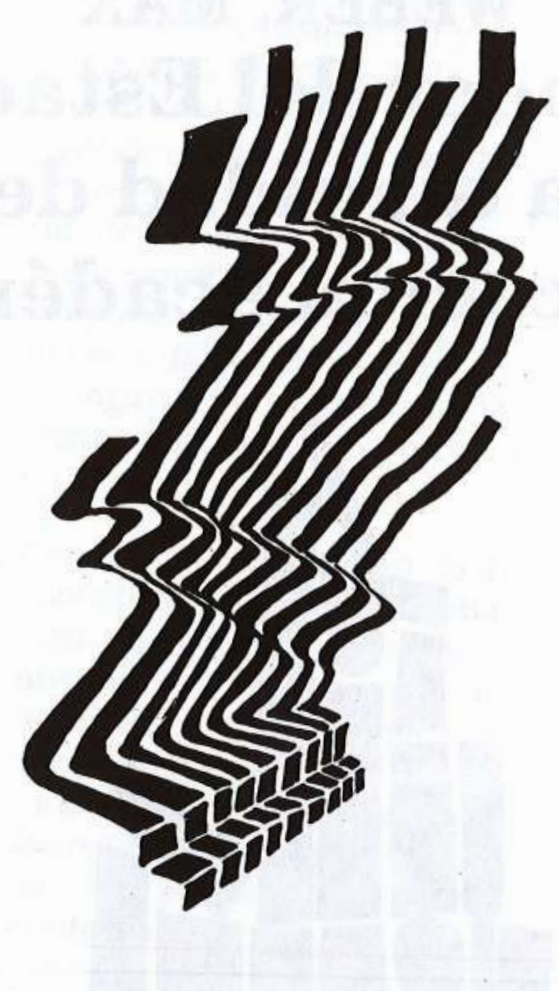

(págs. 39 a 48) y en Notas complementarias a la conferencia de Dresde (págs. 61 a $65)$.

El estudio sobre la cuestión está orientado por un interés fundamentalmente descriptivo que arriba a comparaciones. Por tanto, en rigor, no muestra la validez o preferencla que se pueda dar al sistema universitario alemán sobre el norteamericano; tampoco muestra tales posibilidades en la dirección contraria. Más bien, ofrece una puntualización de los limites que se encuentran en cada uno de ellos.

Esta comparación, propiamente dicha, se extiende al escrito: Las escuelas de comercio: una respuesta (págs. 55 a 59$)$. d. ¿Qué alcances se pueden esperar de una 'descentración' del yo, esto es, en el camino hacia la objetividad en la ciencia y en la vida académica universitaria? Es, entre otros, uno de los interrogantes que da motivo a dos ensayos. Significado de la 'neutralidad ética' en sociologia y en economia (págs. 73 a 81) y La ciencia como una profesión vocacionalmente orientada (págs. 83 a 91).

Weber da lugar a la expresión de la experiencia subjetiva; ésta sin embargo, debe darse fuera del aula (pág 78). Por eso, sugiere que los estudiantes se den a la tarea de "exigir de sus catedráticos en el aula (...):

a) La capacidad de conformarse con el cumplimiento escueto de una tarea dada.

b) Admitir ante todos los hechos, incluso $y$ precisa-

Universidad de Gottingen. Su nombre fue rechazado, entonces, por 'los colegas".

Ç. BIEMEL, Walter. Introducción del editor alemán. A: HUSSERL, E. La idea de la fenomenología. México, F.C.E., 1982, p.13.

2 Weber lo sintetiza así: "Se trata de un sistema que opera a través de compromisos: (1) compromisos de los profesores con toda suerte de cosas admisibles e inadmisibles (...), y (2) compromisos de la oficina de administración en relación con asuntos como: posibilidades de ascenso a la carrera (...), obligaciones de guardar silencio (...)" (p.50). 
mente los que puedan parecer incómodos, y saber esperar las comprobaciones de los hechos de una toma de posición valorizadora.

c) Posponer su propia persona a la causa y, en consecuencia, reprimir la necesidad de exponer en lugar inadecuado sus gustos y demás sentimientos personales (págs. 76/7).

Este tipo de ejercicio académico quizá lleva a comprender que "el ser superados científicamente no es sólo el destino, sino la finalidad de todos nosotros" (pág. 91).

\section{Observación final:}

Resulta interesante observar que 10 de los 14 ensayos fueron publicados en periódi$\cos ^{3}$; interesante porque muestra un intento de realizar la polémica en el escenario público; además, porque es una forma concreta de realizar un Proyecto de Ilustración, entendido como deliberación; en fin, porque se presupone la 'opinión pública' como la población que debe tomar posición sobre la educación universitaria, toda vez que ésta se asume como expresión del espiritu de un pueblo.

Independientemente de lo que estos textos aporten a la sociologia, dos aspectos se pueden ver enriquecidos por los mismos: a) las discusiones filosóficas sobre el proyecto de racionalidad y de modernidad 4; b) la clarificación de lo que puede entenderse como Campo Intelectual de la Educación y, desde éste, las relaciones: sociologia-educación.

\section{GERMAN VARGAS GUILLEN}

Profesor Universidad

Pedagógica Nacional

Facultad de Educación

38 de ellos en el Frankfurter Zeitung.

4 Cf. HABERMAS, J. Theorie des Kommunikatives Handelns. Francfort, 1981; tomo I, pág. 225 ss.

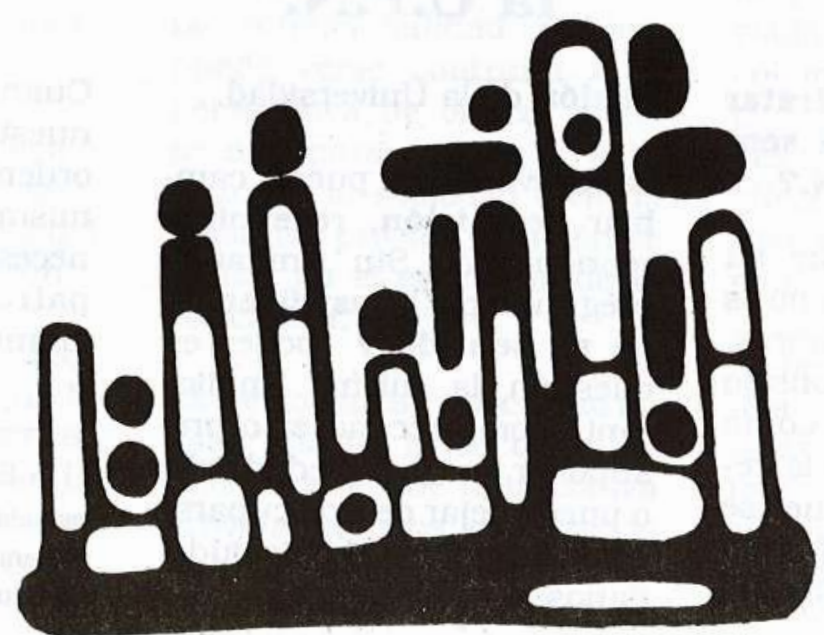

